\title{
Ozone observations by the Gas and Aerosol Measurement Sensor during SOLVE II
}

\author{
M. C. Pitts ${ }^{1}$, L. W. Thomason ${ }^{1}$, J. M. Zawodny ${ }^{1}$, B. N. Wenny ${ }^{2}$, J. M. Livingston ${ }^{3}$, P. B. Russell ${ }^{4}$, J.-H. Yee , $^{5}$ \\ W. H. Swartz ${ }^{5}$, and R. E. Shetter ${ }^{6}$ \\ ${ }^{1}$ NASA Langley Research Center, Hampton, Virginia, USA \\ ${ }^{2}$ Science Applications International Corporation, Hampton, Virginia, USA \\ ${ }^{3}$ SRI International, Menlo Park, California, USA \\ ${ }^{4}$ NASA Ames Research Center, Moffett Field, California, USA \\ ${ }^{5}$ The Johns Hopkins University Applied Physics Laboratory, Laurel, Maryland, USA \\ ${ }^{6}$ National Center for Atmospheric Research, Boulder, Colorado, USA
}

Received: 1 July 2005 - Published in Atmos. Chem. Phys. Discuss.: 13 October 2005

Revised: 4 May 2006 - Accepted: 31 May 2006 - Published: 6 July 2006

\begin{abstract}
The Gas and Aerosol Measurement Sensor (GAMS) was deployed aboard the NASA DC-8 aircraft during the second SAGE III Ozone Loss and Validation Experiment (SOLVE II). GAMS acquired line-of-sight (LOS) direct solar irradiance spectra during the sunlit portions of ten science flights of the DC- 8 between 12 January and 4 February 2003. Differential line-of-sight (DLOS) optical depth spectra are produced from the GAMS raw solar irradiance spectra. Then, DLOS ozone number densities are retrieved from the GAMS spectra using a multiple linear regression spectral fitting technique. Both the DLOS optical depth spectra and retrieved ozone data are compared with coincident measurements from two other solar instruments aboard the DC- 8 platform to demonstrate the robustness and stability of the GAMS data. The GAMS ozone measurements are then utilized to evaluate the quality of the Wulf band ozone cross sections, a critical component of the SAGE III aerosol, water vapor, and temperature/pressure retrievals. Results suggest the ozone cross section compilation of Shettle and Anderson currently used operationally in SAGE III data processing may be in error by as much as $10-20 \%$ in the Wulf bands, and their lack of reported temperature dependence is a significant deficiency. A second, more recent, cross section database compiled for the SCIAMACHY satellite mission appears to be of much better quality in the Wulf bands, but still may have errors as large as 5\% near the Wulf band absorption peaks, which is slightly larger than their stated uncertainty. Additional laboratory measurements of the Wulf band cross sections should be pursued to further reduce their uncertainty and better quantify their temperature dependence.
\end{abstract}

Correspondence to: M. C. Pitts

(michael.c.pitts@nasa.gov)

\section{Introduction}

The second SAGE III Ozone Loss and Validation Experiment (SOLVE II) was an international field campaign based in Kiruna, Sweden during January and February 2003. The SOLVE II mission employed the NASA DC-8 aircraft, balloon platforms, and ground-based instruments to acquire an intensive set of measurements during the Arctic winter for the study of polar ozone loss processes and validation of the Stratospheric Aerosol and Gas Experiment (SAGE) III data products. The NASA DC-8 instrument payload included a broad range of in situ, lidar, and passive remote sensors. The Gas and Aerosol Measurement Sensor (GAMS) was one of three solar-viewing instruments flown aboard the NASA DC-8 to collect line-of-sight (LOS) measurements of atmospheric transmittance for SAGE III instrument validation. In addition to GAMS, the Ames Airborne Tracking Sunphotometer (AATS-14) (Livingston et al., 2005; Russell et al., 2005) and the NCAR Direct beam Irradiance Airborne Spectrometer (DIAS) (Shetter and Muller, 1999; Swartz et al., 2005) were collecting direct Sun measurements from the DC-8 during SOLVE II.

SAGE III, launched aboard the Russian Meteor 3-M spacecraft in December 2001, is the latest in the SAGE series of solar occultation satellite instruments that infers trace gas and aerosol extinction profiles from measurements of atmospheric transmission along the LOS between the spacecraft and the Sun (Thomason et al., 1999). SAGE III provides continuous spectral coverage between 280 and $1030 \mathrm{~nm}$ at $\sim 1$-nm resolution, which permits the measurement of multiple trace gas species and multi-wavelength measurements of broadband extinction by aerosols. A fundamental product of SAGE III are profiles of ozone number density

Published by Copernicus GmbH on behalf of the European Geosciences Union. 

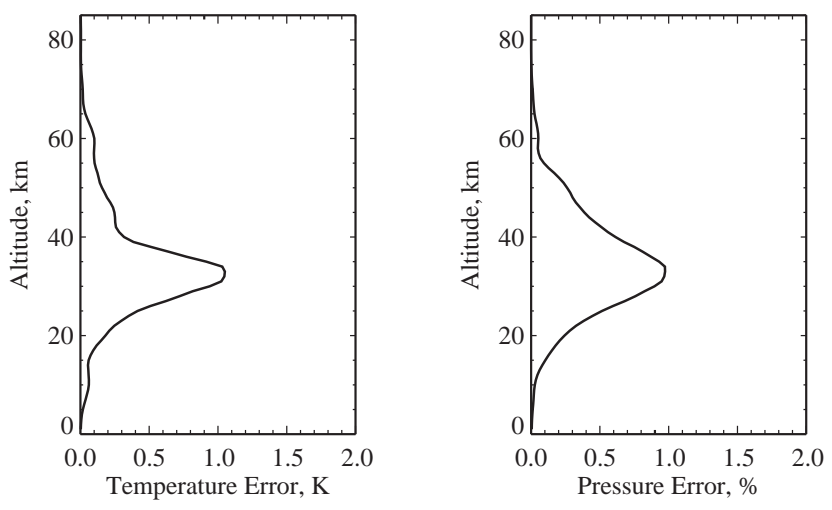

Fig. 1. Estimated systematic error in SAGE III temperature and pressure retrievals due to a $1 \%$ bias in the ozone absorption cross sections (Pitts, 1999).

retrieved from multi-spectral measurements of the strong, well-characterized Chappuis ozone absorption feature centered near $600 \mathrm{~nm}$. In other SAGE III spectral regions such as the oxygen A-band centered near $765 \mathrm{~nm}$ (utilized for retrieval of temperature and pressure), 940-nm water vapor band, and 676-, 755-, and 868-nm aerosol channels, ozone is a significant interfering species and must be cleared from the measurements as part of the retrieval process. Operationally, the interfering ozone optical depth contributions in these channels are estimated as the spectrally-integrated product of the ozone column density retrieved independently from the SAGE III Chappuis band measurements and reference ozone molecular absorption cross-sections tabulated for the ozone Wulf bands that extend from near 730 to $1030 \mathrm{~nm}$ (NASA Langley Research Center, 2002). As a consequence, the success of the SAGE III temperature/pressure, water vapor, and aerosol retrievals is reliant on accurate knowledge of the Wulf band absorption cross sections. Currently, however, significant uncertainty exists in both the magnitude and temperature dependence of the ozone cross sections in the Wulf bands. For instance, the cross section compilation of Shettle and Anderson (1995) (hereafter referred to as SA) currently utilized in SAGE III data processing and the reference cross section data set produced for the SCanning Imaging Absorption spectroMeter for Atmospheric CHartographY (SCIAMACHY) satellite project (Bogumil et al., 2003) differ by more than $10 \%$ in regions of the Wulf bands.Figure 1 illustrates the estimated systematic error in SAGE III retrieved temperature and pressure profiles due to just a $+1 \%$ bias in the ozone molecular cross sections in the $\mathrm{O}_{2}$ A-band region (Pitts, 1999). This effect does not account for any error in the cross section temperature dependence, which would likely affect the shape of the ozone cross section across the A-band and produce larger and less predictable errors in the retrieved products. Thomason and Taha (2003) have also attributed bias observed in the SAGE III 755-nm aerosol extinction to errors in the SA ozone cross section compilation. Clearly, the discrepancies in the reference ozone cross sections need to be reconciled to ensure the SAGE III products are of highest quality.

The overarching goal of this work is to assess the quality of reference Wulf band ozone cross sections using atmospheric measurements from GAMS during the SOLVE II mission. GAMS acquired LOS solar spectra on ten science flights during SOLVE II. Data from three of the flights are examined in detail. First, differential line-of-sight (DLOS) optical depth spectra are produced from the GAMS raw solar irradiance spectra. Then, ozone number densities are retrieved from GAMS DLOS optical depth spectra using a multiple linear regression (MRL) spectral fitting technique. Both the DLOS optical depth spectra and retrieved ozone number densities are compared with simultaneous measurements from independent solar instruments aboard the DC-8 (AATS-14 and DIAS) to establish the robustness and stability of the GAMS measurements. The GAMS atmospheric spectra then serve as the basis for evaluating the accuracy of the laboratory measurements of the Wulf band ozone cross sections reported in the SA compilation, as well as, the SCIAMACHY reference data set. The quality of the spectral fits of the GAMS Wulf band measurements provides insight to the accuracy of the reference cross sections. This assessment fulfills one of the major science goals of the GAMS experiment during SOLVE II.

\section{GAMS measurements during SOLVE II}

\subsection{Instrument description}

The GAMS instrument measures the direct solar transmittance along the LOS between the aircraft and the Sun in 1024 spectral channels from 430 to $1030 \mathrm{~nm}$. The instrument package includes spectrometer, solar imager, and telescope assemblies that are pointed at the Sun by a two-axis gimbaled mirror. The grating spectrometer and detectors were developed under NASA's Instrument Incubator Program and have exceptionally high performance (Refaat et al., 2005). The spectrometer disperses the spectral region from 430 to $1030 \mathrm{~nm}$ onto two 512-element hybrid diode-CCD arrays using a dichroic beamsplitter. Spectral coverage is nearly continuous except for a gap of approximately $20 \mathrm{~nm}$ centered near $730 \mathrm{~nm}$. The pixel-to-pixel spacing in wavelength is a uniform $0.58 \mathrm{~nm} /$ pixel across both detectors. The spectral resolution varies across each detector between values of 0.7 and $1.0 \mathrm{~nm}$ on the short-wavelength detector and 1.0 and $2.0 \mathrm{~nm}$ on the long-wavelength detector. The combination of a diode array, for the primary light gathering and conversion of incident photon into electrons, with a pair of CCD-based serial shift registers endows this detector with a 20 million electron full well and a small 10-micrometer pixel pitch. The entire detector assembly is referred to as the photon-to-bits board and achieves a shot noise limited signal-to-noise ratio 


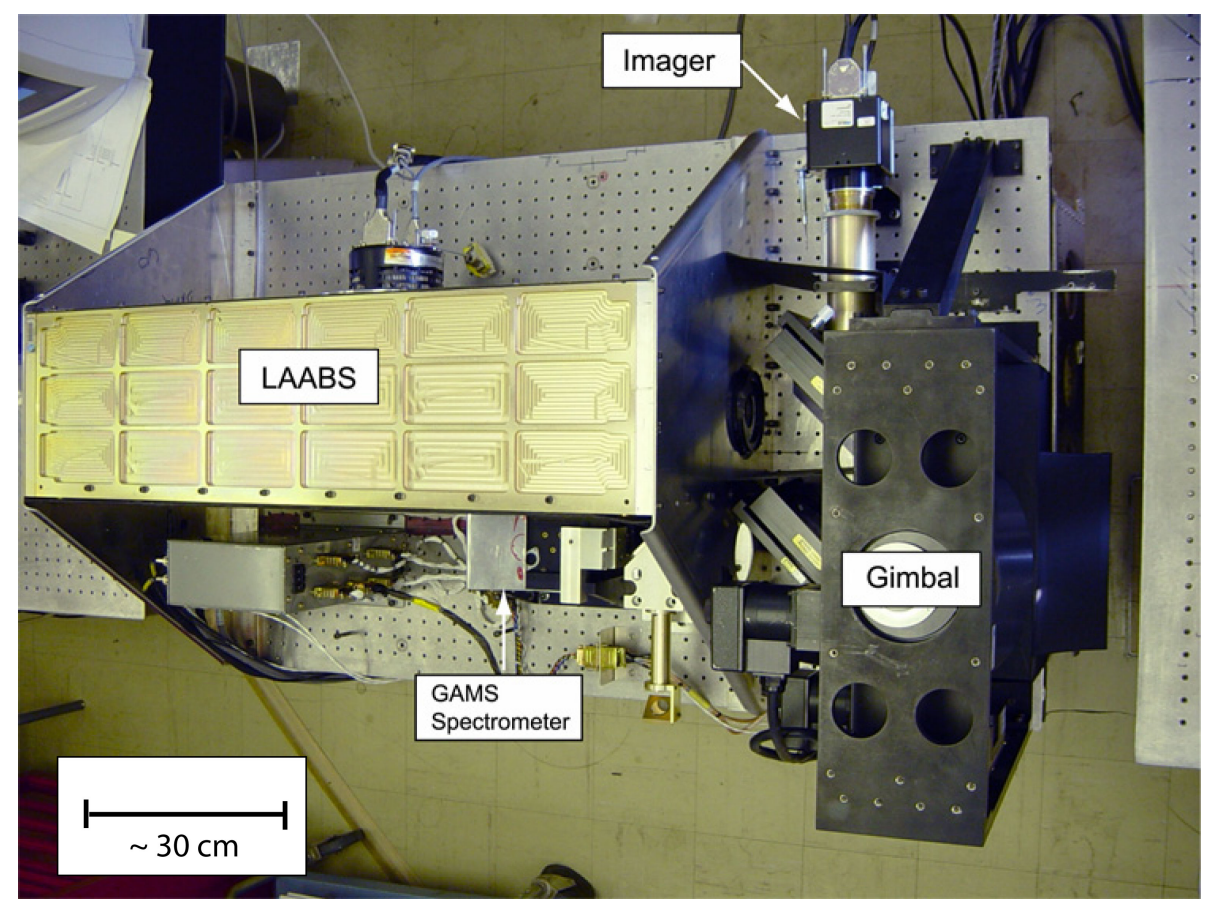

Fig. 2. GAMS and LAABS instrument configuration for the SOLVE II campaign.

Table 1. DC-8 flight dates and time ranges of GAMS solar spectra during SOLVE II.

\begin{tabular}{lllllr}
\hline Date & Start time & Stop time & Legs & SZA Range & No. Spectra \\
\hline $12 / 01 / 2003$ & $10: 09: 14$ & $12: 01: 44$ & 4 & $92.2^{\circ}-89.4^{\circ}$ & 349200 \\
$14 / 01 / 2003$ & $09: 47: 44$ & $12: 15: 44$ & 4 & $91.2^{\circ}-83.7^{\circ}$ & 455040 \\
$16 / 01 / 2003$ & $09: 46: 44$ & $11: 22: 14$ & 3 & $90.5^{\circ}-89.8^{\circ}$ & 394560 \\
$19 / 01 / 2003$ & $08: 34: 14$ & $13: 42: 44$ & 7 & $92.2^{\circ}-83.0^{\circ}$ & 1051920 \\
$21 / 01 / 2003$ & $14: 36: 44$ & $17: 05: 44$ & 1 & $87.1^{\circ}-83.7^{\circ}$ & 1582380 \\
$24 / 01 / 2003$ & $09: 49: 14$ & $11: 59: 44$ & 5 & $90.1^{\circ}-89.6^{\circ}$ & 595440 \\
$26 / 01 / 2003$ & $11: 50: 44$ & $13: 46: 44$ & 2 & $92.2^{\circ}-89.4^{\circ}$ & 271440 \\
$29 / 01 / 2003$ & $10: 16: 44$ & $11: 43: 44$ & 4 & $92.2^{\circ}-89.4^{\circ}$ & 361440 \\
$31 / 01 / 2003$ & $09: 37: 44$ & $10: 39: 14$ & 2 & $92.2^{\circ}-89.4^{\circ}$ & 289440 \\
$02 / 02 / 2003$ & $10: 45: 14$ & $12: 47: 44$ & 3 & $87.6^{\circ}-89.5^{\circ}$ & 479520 \\
\hline
\end{tabular}

of 4000:1 as it is digitized to 16 bits. The spectra are acquired at a rate of $180 \mathrm{~Hz}$ with a dynamic range above the noise floor in excess of 14 bits. The spectrometer is fed with an off-axis parabolic telescope and has a 0.5 arc-minute vertical FOV. The solar imager is a commercially available $1024 \times 1024$ CCD camera with each pixel having a FOV of 0.3 arc-minutes. A narrow band filter at $865 \mathrm{~nm}$ is used in both the imager and the Sun position sensor in the gimbal servo pointing system and allows pointing errors to be measured and modeled relative to the imager data and enables a means of evaluating scene homogeneity.

For the SOLVE II deployment, GAMS was configured with the Langley Airborne A-Band Spectrometer (LAABS) (Pitts et al., 2003). The LAABS instrument acquired high- resolution measurements of the $\mathrm{O}_{2}$ A-band absorption feature near $765 \mathrm{~nm}$ for validation of the SAGE III $\mathrm{O}_{2}$ A-band forward model. Both instruments shared the common pointing system to view the Sun through an optical view port located on the starboard side of the DC- 8 cabin just forward of the wing. The configuration of the GAMS and LAABS instruments for the SOLVE II deployment on the DC- 8 is shown in Fig. 2.

\subsection{Optical depth measurements}

GAMS acquired atmospheric spectra during the sunlit portions of ten science flights of the NASA DC- 8 between 12 January and 4 February 2003. The spectra were acquired 
12 UTC on 19 January, 2003 on the $460.0 \mathrm{~K}$ surface
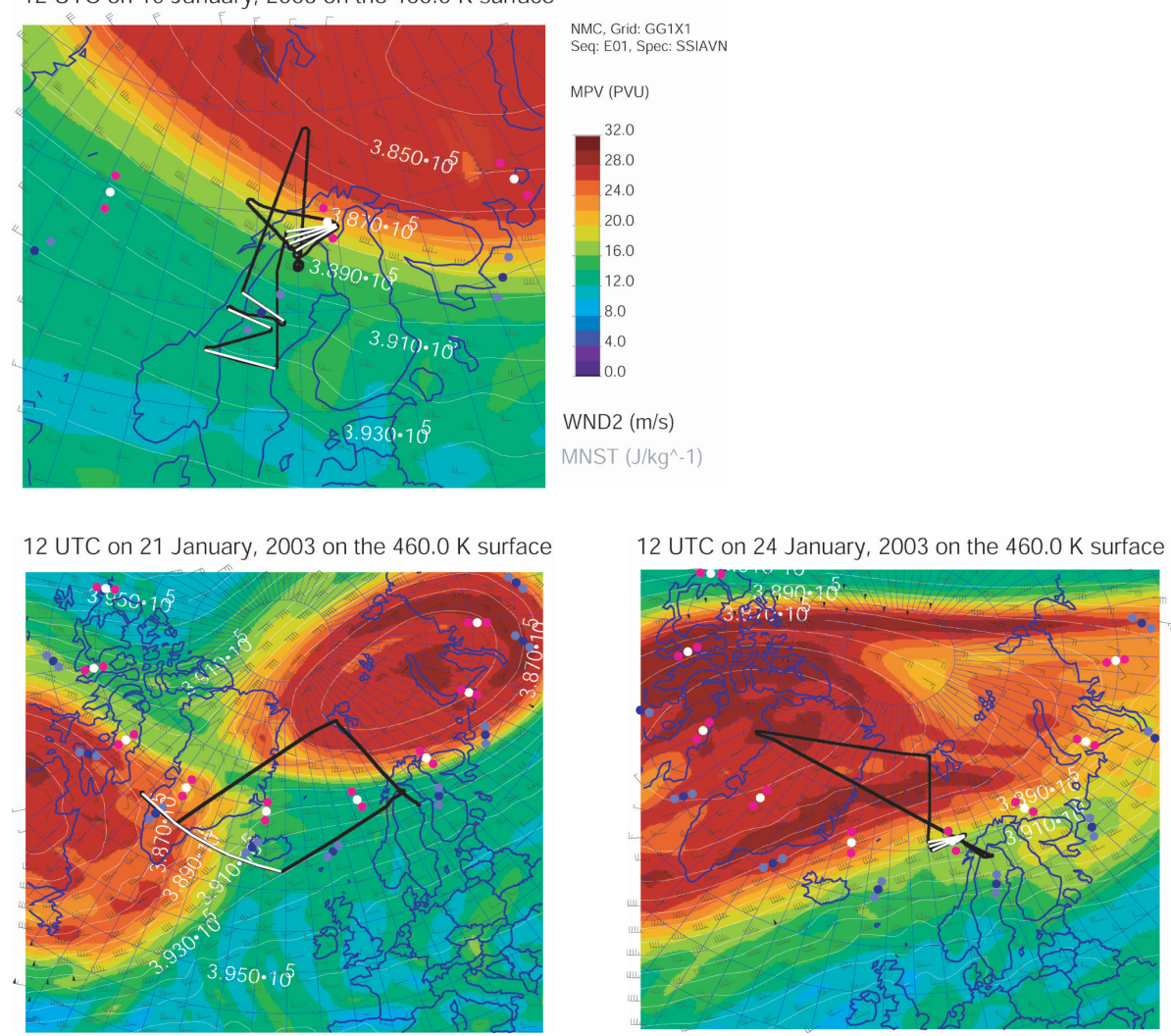

Fig. 3. DC-8 flight tracks (black) superimposed on $12 \mathrm{Z}$ analysis maps of modified potential vorticity (MPV) for the $460 \mathrm{~K}$ isentropic surface. White legs indicate "Sun" runs. White and blue points mark occultations by SAGE III and POAM III, respectively. Maps were produced by L. Lait, M. Schoeberl, and P. Newman.

at $180 \mathrm{~Hz}$ and archived in four-second data packets along with synchronous aircraft navigation, atmospheric temperature, pressure, and moisture data provided through the DC- 8 Information Collection and Transmission System (ICATS). GAMS quick-look optical depth spectra and solar imager data were displayed in real-time at the operator console. Table 1 summarizes the GAMS measurements acquired during SOLVE II. The DC-8 flight altitudes for SOLVE II were primarily restricted to the lower stratosphere with Sun legs typically executed at $10.8 \mathrm{~km}(35000 \mathrm{ft})$, but a few Sun legs were also flown at $9.5 \mathrm{~km}$ and $12 \mathrm{~km}$. In this study, we present results from three flights: 19,21 , and 24 January. The DC-8 flight tracks for these days are shown in Fig. 3.

The GAMS raw spectra consist of signal counts versus wavelength. Examples of GAMS raw spectra acquired over a range of solar zenith angles during the 19 January flight are shown in Fig. 4. A number of features are visible in the raw spectra including the Chappuis ozone absorption band near $600 \mathrm{~nm}$, molecular oxygen A- and B-bands ( $\sim 765$ and $688 \mathrm{~nm}$, respectively), and solar Fraunhofer lines near $860 \mathrm{~nm}$. The spectra also possess weaker signatures of $\mathrm{H}_{2} \mathrm{O}$, $\mathrm{NO}_{2}$, and $\left(\mathrm{O}_{2}\right)_{2}$. The gap between the short- and longwavelength detectors can be seen near $730 \mathrm{~nm}$. The steep ramp in signal at the beginning of the long-wavelength detector (near $740 \mathrm{~nm}$ ) is due to the spectral character of the dichroic beamsplitter.

GAMS raw spectra are typically converted into LOS optical depth spectra by normalizing the measured raw spectra, $\mathrm{I}(\lambda)$, by a reference solar spectrum, $\mathrm{I}_{o}(\lambda)$

$\tau(\lambda)=-\ln \left[\frac{I(\lambda)}{I_{o}(\lambda)}\right]$

Ideally, the reference $I_{O}$ spectrum would be an exoatmospheric spectrum derived through standard Langley calibration techniques applied to GAMS measurements obtained from a high elevation location such as Mauna Loa, Hawaii. We have attempted to derive an accurate $I_{o}$ spectrum from GAMS measurements acquired at our sea level facility in Hampton, Virginia; however, to date, this effort has not been successful. As a result, this study is based on GAMS differential line-of-sight (DLOS) optical depth spectra produced by normalizing each measured spectrum by a reference spectrum acquired at relatively low air mass (small solar zenith angle) during the same flight. DLOS optical depth spectra produced in this manner provide an accurate measure of variability along the flight tracks and are not 


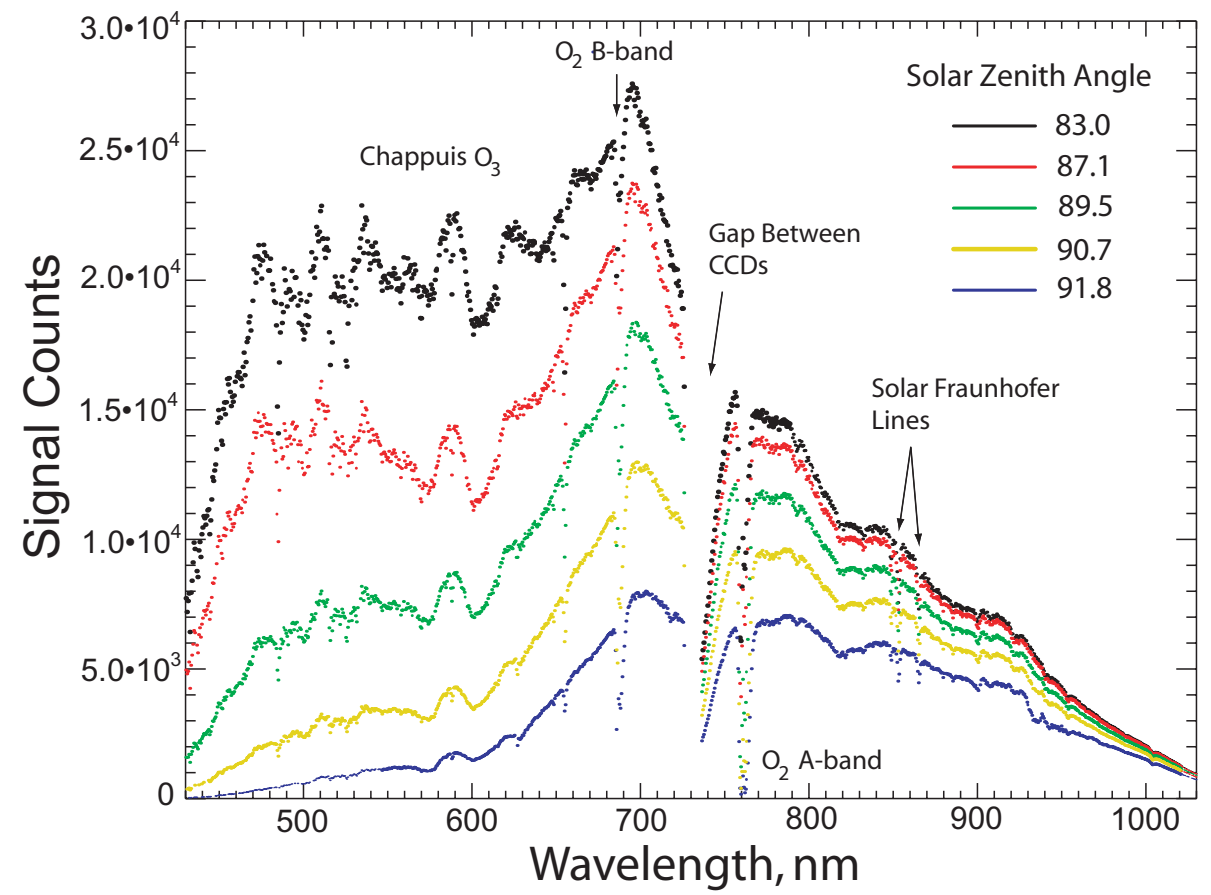

Fig. 4. GAMS raw spectra acquired at various solar zenith angles during the flight of 19 January 2003.

dependent on knowledge of absolute radiometric calibration. In the example shown in Fig. 4, the spectrum acquired at a solar zenith angle of $83^{\circ}$ (black curve) would be the reference spectrum used to convert the raw spectra into DLOS optical depth spectra. An example of the resulting GAMS DLOS optical depth spectra from the flight of 19 January 2003 is shown in Fig. 5. The gas species absorption features, including the ozone Wulf bands, are more clearly discernible in the DLOS optical depth spectra. All analyses of the GAMS data presented in this work are based on four-second data packet averages (720 spectra), yielding DLOS optical depth spectra with a measurement precision of better than $0.05 \%$.

To establish the robustness of the GAMS atmospheric spectra acquired during SOLVE II, GAMS DLOS optical depth measurements were compared with coincident measurements from AATS-14, an airborne sun photometer that was also flown aboard the DC-8. AATS-14 measures the direct beam solar transmission in fourteen discrete spectral channels from 354 to $2138 \mathrm{~nm}$ to produce aerosol optical depth and slant column ozone and water vapor density (Livingston et al., 2005; Russell et al., 2005). First flown in 1996, AATS-14 has a long measurement history and a heritage that includes its predecessor, AATS-6. The data quality of AATS-6 and -14 is well documented (e.g., Russell et al., 1993a, 1993b; Schmid et al., 2003). In particular, AATS14 ozone retrievals have been compared to Brewer and Dobson measurements at Mauna Loa Observatory. Agreement is within $1-2 \%$ when $\mathrm{SZA}>81^{\circ}$, i.e., angles typical of the SOLVE II DC-8 Arctic flights (Livingston et al., 2005).

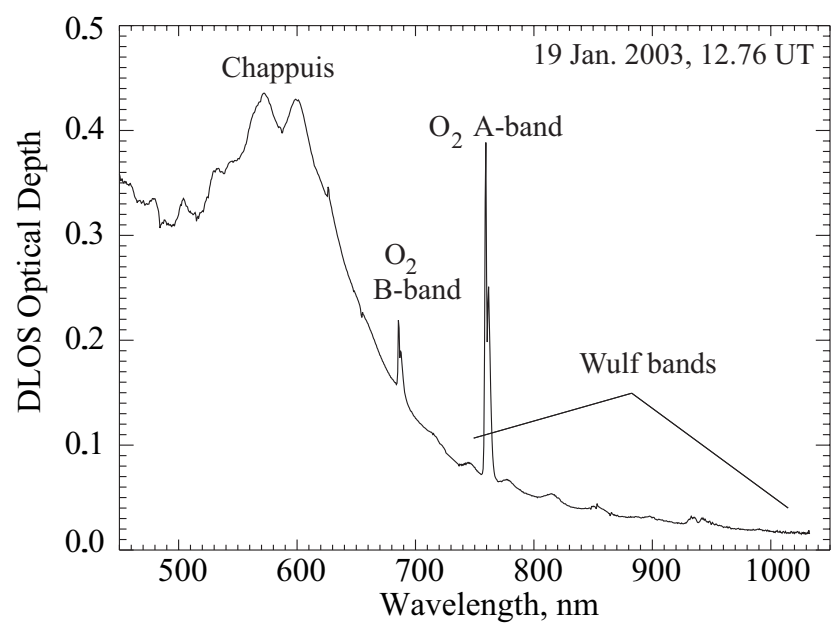

Fig. 5. Example of GAMS DLOS optical depth spectra produced from measurements acquired during the 19 January 2003 flight.

Shown in Fig. 6 are the GAMS/AATS-14 comparisons from the 21 January flight at six AATS-14 channel wavelengths that fall within the GAMS spectral range (519.4, 604.4, $675.1,865.5,940.6$, and $1019 \mathrm{~nm})$. To facilitate the comparisons, the GAMS DLOS optical depth measurements have been normalized by the AATS-14 LOS optical depth value near the mid-point of the flight at 15.85 UT. Relatively large LOS optical depth values are observed in the three channels surrounding the peak of the Chappuis band due to the 

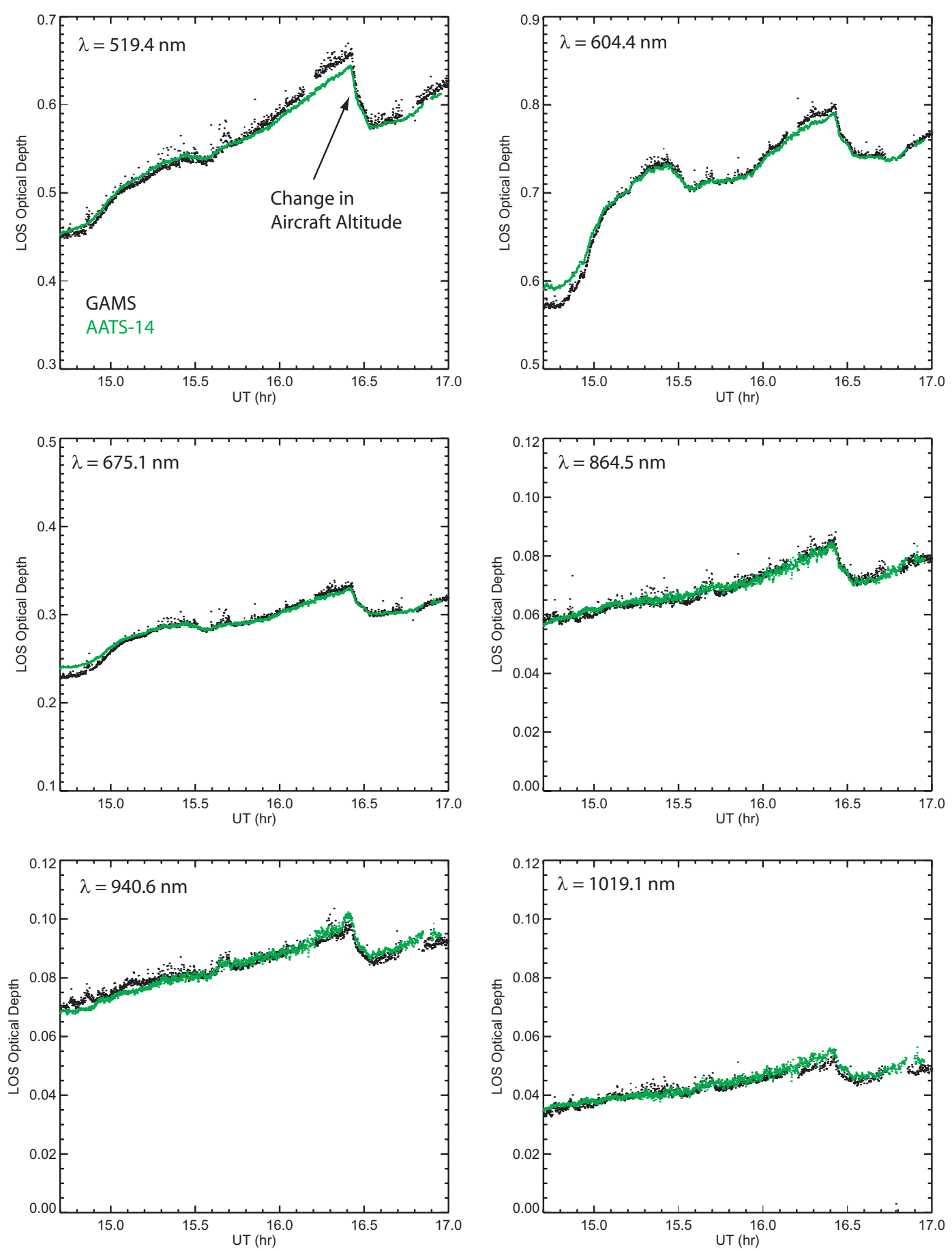

Fig. 6. Comparison of GAMS (black points) and AATS-14 (green points) LOS optical depth at six AATS-14 channel wavelengths for the DC-8 flight of 21 January 2003. GAMS data are normalized by the AATS-14 LOS optical depth values from 15.85 UT.

combination of strong ozone absorption and Rayleigh scattering. At the three longest wavelengths, the ozone absorption and Rayleigh scattering contributions are significantly weaker with broadband aerosol becoming the dominant component, resulting in LOS optical depths that are about an order of magnitude less than at $604.4 \mathrm{~nm}$. The "hump" in LOS optical depth observed between 15.0 UT and 15.5 UT in the 604.4-nm data, and to a lesser extent in the 519.4-nm and 675.1-nm data, is indicative of the ozone spatial variability encountered along the 21 January flight track. Agreement between GAMS and AATS-14 optical depth measurements is excellent with small mean and root-mean-squared (RMS) 
differences at all wavelengths (see Table 2). These comparisons confirm that GAMS and AATS-14 observed nearly the same atmospheric variability along the flight path and GAMS DLOS optical depth data is of good science quality. The GAMS DLOS optical depth spectra serve as the basis of the analyses presented below.

\section{Spectral fitting and ozone retrievals}

We have adopted a multiple linear regression (MLR) approach (Bevington, 1969) for the simultaneous fitting and retrieval of DLOS ozone column density from the GAMS DLOS optical depth spectra. This technique is similar to that used operationally in the SAGE III ozone retrievals (NASA Langley Research Center, 2002). The basic approach is to fit the GAMS DLOS optical depth spectra with a regression model that accounts for the spectral dependence of all relevant gas species' absorption features, as well as, broadband aerosol and molecular (Rayleigh) scattering. The observed DLOS total optical depth, $\tau(\lambda)$, for a single GAMS channel is expressed as the sum of the $\mathrm{O}_{3}, \mathrm{H}_{2} \mathrm{O},\left(\mathrm{O}_{2}\right)_{2}, \mathrm{NO}_{2}$, molecular scattering, and aerosol components:

$$
\begin{gathered}
\tau(\lambda)=n_{O_{3}} \sigma_{O_{3}}(\lambda)+n_{H_{2} O} \sigma_{H_{2} O}(\lambda)+n_{O_{2} \cdot O_{2}} \sigma_{O_{2} \cdot O_{2}}(\lambda)+ \\
n_{N O_{2}} \sigma_{N O_{2}}(\lambda)+n_{\text {air }} \sigma_{\text {Ray }}(\lambda)+\tau_{\text {aer }}(\lambda)
\end{gathered}
$$

where the $n_{i}$ and $\sigma_{i}$ represent the DLOS column density and cross section of the individual gas species, $n_{\text {air }}$ is the neutral air column density, $\sigma_{\text {ray }}$ is the cross section for Rayleigh scattering, and $\tau_{\text {aer }}(\lambda)$ represents the aerosol optical depth. The wavelength dependence of the aerosol optical depth is expressed as

$\tau_{\mathrm{aer}}(\lambda)=\tau_{\mathrm{aer}}\left(\lambda_{o}\right)\left[\frac{\lambda_{o}}{\lambda}\right]^{\alpha}$

where $\lambda_{o}$ is a reference wavelength and $\alpha$ is the Angstrom coefficient. For this study, $\alpha$ was assigned a value of 1.8 based on analyses of SAGE III multi-wavelength aerosol extinction measurements over the Arctic during the SOLVE II mission timeframe. Water vapor absorption across the GAMS spectral region was modelled using empirical orthogonal functions. These functions, which represent the spectral shape of the DLOS water vapor optical depth, were created from synthetic GAMS spectra produced from MODTRAN calculations for a number of diverse profiles in the upper troposphere and stratosphere. We found that only the most significant functions were required within the MLR routine to account for the weak water vapor absorption spectra observed during most flight legs. The remaining gas species absorption cross-sections and Rayleigh scattering cross sections are considered to be known quantities, leaving the gas species and neutral air column densities and aerosol optical depth to be determined as coefficients of the regression analysis. The molecular cross section databases used in the model are the
Table 2. GAMS/AATS-14 optical depth comparisons from 21 January 2003.

\begin{tabular}{ccc}
\hline Wavelength (nm) & Mean Diff. (\%) & RMS Diff. (\%) \\
\hline 519.4 & 0.53 & 1.95 \\
604.4 & -0.13 & 1.78 \\
675.1 & -0.33 & 2.43 \\
864.5 & 0.02 & 3.05 \\
940.6 & 0.31 & 3.33 \\
1019.1 & -2.38 & 5.04 \\
\hline
\end{tabular}

same as those used in the SAGE III operational data processing (see NASA Langley Research Center, 2002 for more detail). The cross sections for Rayleigh scattering are computed from the Bucholtz (1995) formulation.

The spectral range of the fits is limited to the region near the peak of the Chappuis ozone feature (500 to $680 \mathrm{~nm}$ ) and the Wulf bands (740 to $1020 \mathrm{~nm}$ ). In addition, we have excluded the intense $\mathrm{O}_{2}$ A-band feature between 758 and $775 \mathrm{~nm}$. The GAMS measurements within the selected spectral regions are fit in a piecewise continuous fashion. A typical example of an MLR fit of the GAMS DLOS optical depth spectra is shown in Fig. 7. The top panel shows a measured GAMS DLOS optical depth spectrum from the flight of 19 January (red points) with the fitted spectrum overlaid (solid line). The relative differences between the measured and fitted DLOS optical depths are shown in the bottom panel to illustrate the quality of the fits. The optical depth residuals are generally less than a few percent, but at longer wavelengths, the relative residuals become increasingly noisy as the absolute magnitude of the DLOS optical depths decreases.

Using this MLR spectral fitting approach, DLOS ozone column densities were retrieved from the GAMS optical depth measurements for all ten SOLVE II flights. Although ozone absorbs throughout the entire spectral range of the GAMS measurements, the retrieved ozone column density coefficients are effectively determined from the fit of the strong Chappuis absorption band feature near $600 \mathrm{~nm}$. Based on propagation of the DLOS optical depth measurement uncertainties through the regression analysis, the estimated precision of the retrieved DLOS ozone number densities is better than $0.1 \%$ for the magnitude of DLOS ozone number densities encountered on most flights. The accuracy of the ozone retrievals is more difficult to assess and includes uncertainty in the both the regression model and instrument characterization. Uncertainty in the Chappuis ozone cross sections has been estimated by Orphal (2003) to be on the order of a few percent and could introduce a slight bias in the retrieved DLOS ozone density. Uncertainty in the other gas species absorption cross sections is not crucial since the Chappuis ozone feature dominates the overall shape of the spectra. On the other hand, the quality of the baseline (aerosol and 

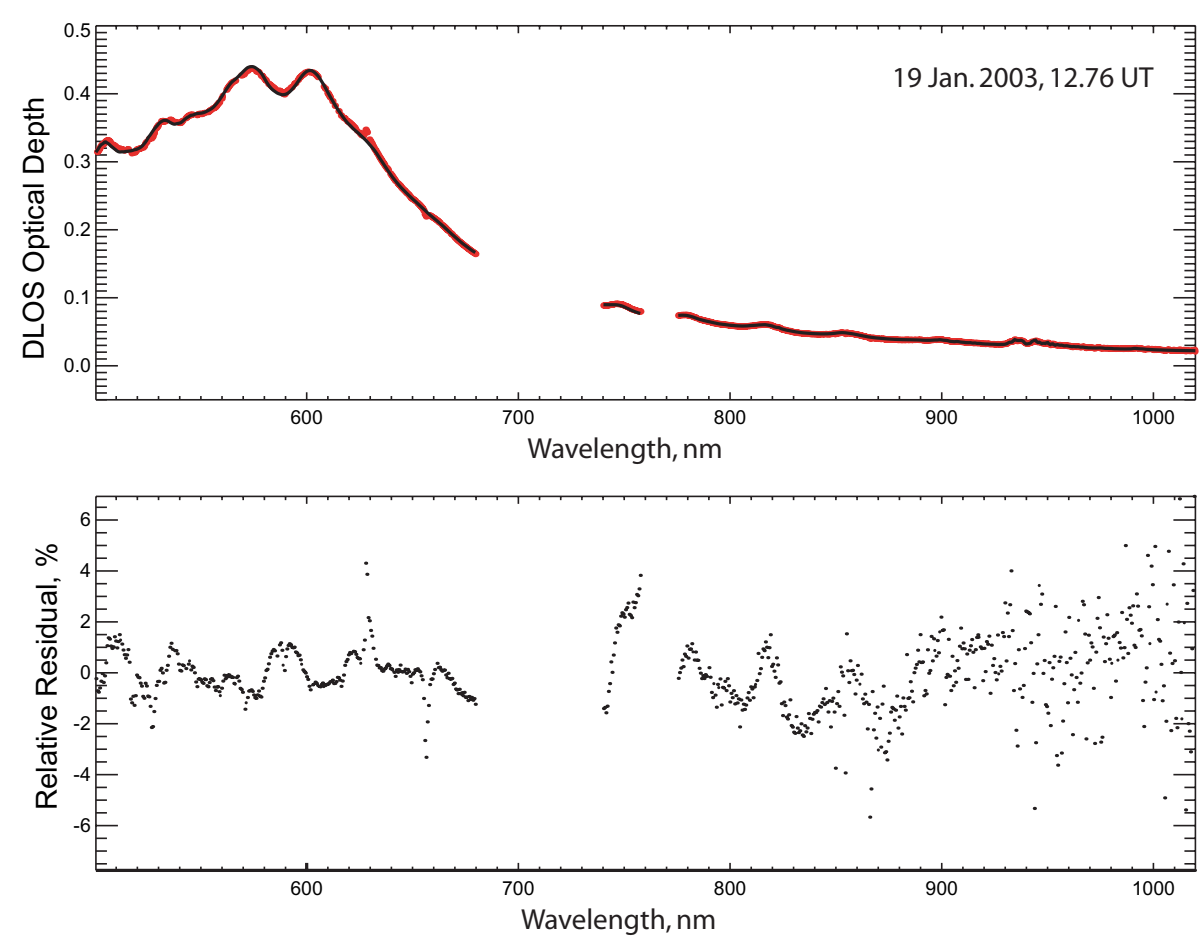

Fig. 7. Example of MLR fit to GAMS DLOS optical depth spectrum. Top panel shows measured GAMS spectrum (red dots) and MLR fit (solid line). Bottom panel shows relative optical depth residuals between measurements and fit.

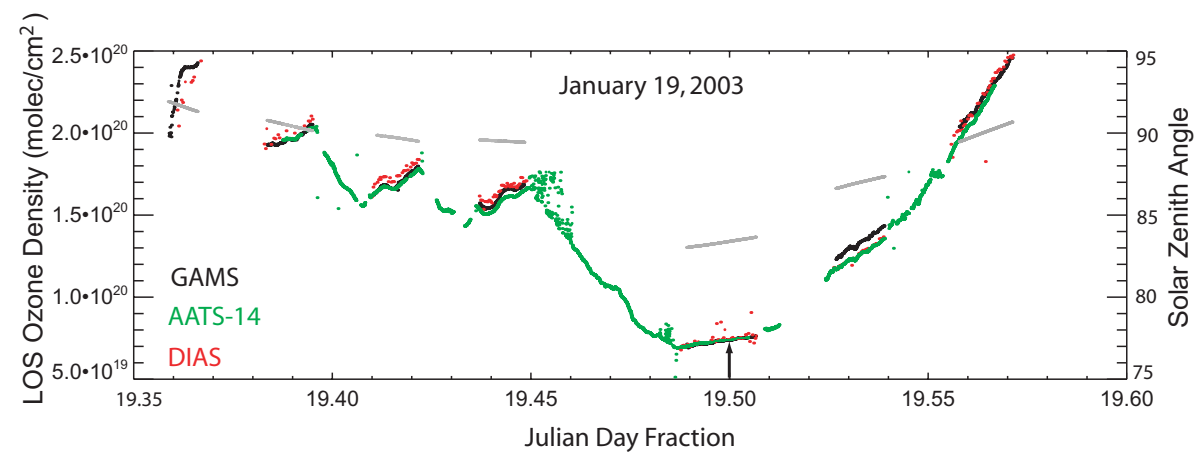

Fig. 8. Comparison of GAMS (black), AATS-14 (green), and DIAS (red) LOS ozone densities for the flight of 19 January 2003. GAMS DLOS data are normalized by the AATS-14 LOS value at the time indicated by the arrow. The solar zenith angle of the measurements is indicated by the light grey line.

Rayleigh) fits is important. Several different aerosol models were tested, but overall, the choice of aerosol model had minimal impact on the ozone retrievals. To a large extent, instrument characterization uncertainties are negated by utilizing optical depth as the basis for the retrievals. However, although GAMS performance was exceptionally stable throughout most flights, small drifts in instrument response within an acquisition flight leg could introduce subtle and hard to detect errors.

To evaluate the overall quality of the ozone retrievals, we compared the GAMS DLOS ozone measurements with coincident AATS-14 and DIAS ozone data from three different flights (see Livingston et al., 2005 and Swartz et al., 2005 for a more detailed discussion of the AATS-14 and DIAS ozone analyses). For these comparisons, the GAMS DLOS data were normalized by an AATS-14 LOS ozone column density value from each flight. Shown in Fig. 8 are the GAMS, AATS, and DIAS LOS ozone number densities from the DC8 flight of 19 January 2003. This flight began with a series of four "Sun runs" at similar solar zenith angles near $90^{\circ}$ designed to coincide with a SAGE III occultation event, the aircraft then flew south for two Sun runs in mid-latitude air at zenith angles near $83^{\circ}$ and $87^{\circ}$, and then north again for the final Sun run at a solar zenith angle near $90^{\circ}$. The 


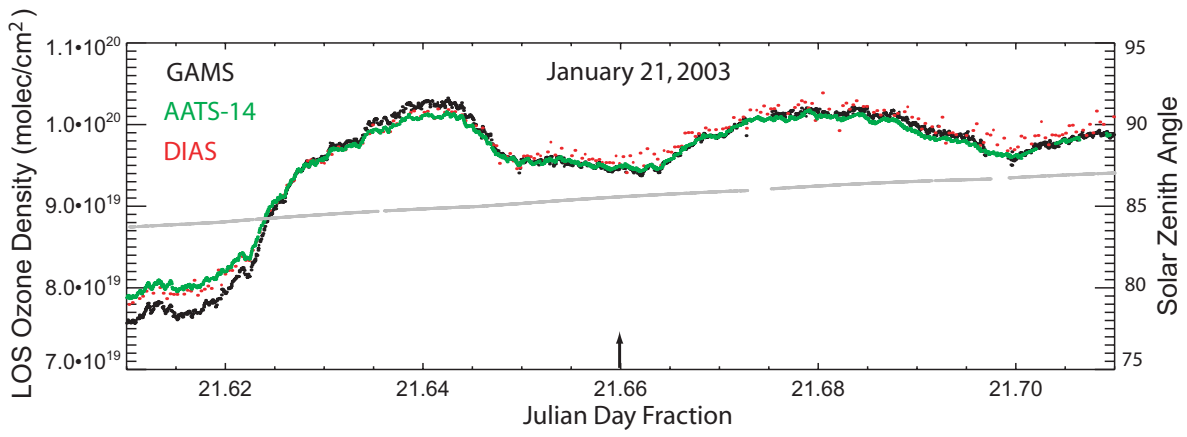

Fig. 9. Same as Fig. 8, except for the flight of 21 January 2003.

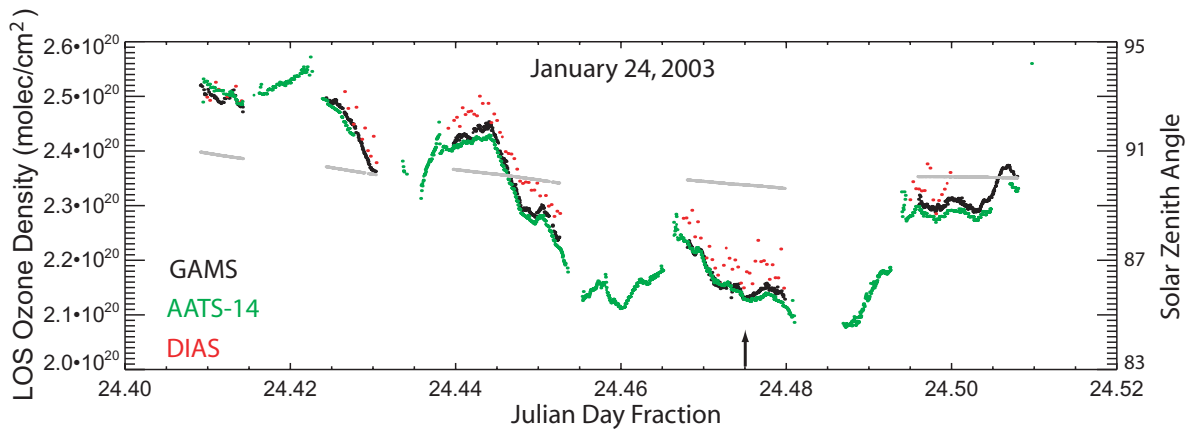

Fig. 10. Same as Fig. 8, except for the flight of 24 January 2003.

data from all three instruments are in excellent agreement throughout all legs of the flight. The mean GAMS minus AATS-14 differences are $1.65 \%$ and RMS differences are $2.67 \%$. Although significant ozone spatial variability was encountered during this flight, much of the leg-to-leg variation in the observed LOS ozone, especially the dramatic decrease at 19.5 Julian day fraction, is related to the solar zenith angle of the measurements. At smaller solar zenith angles, the LOS through the ozone layer is much shorter than at larger solar zenith angles, resulting in the small LOS ozone column densities. The comparisons for the 21 January and 24 January flights, shown in Figs. 9 and 10, indicate similar agreement between the three instruments with GAMS minus AATS-14 mean and RMS differences of $-0.29 \%$ and $2.79 \%$ for the 21 January flight and $0.04 \%$ and $1.00 \%$ for the 24 January flight. While the absolute magnitude of the GAMS ozone data cannot be validated through these types of comparisons, GAMS clearly observes the same ozone variability as AATS and DIAS and exhibits exceptional instrument stability during the flights. Based on the excellent agreement between GAMS and AATS-14 DLOS optical depth measurements and the GAMS, AATS-14, and DIAS ozone observations, we conclude the GAMS spectra are of sufficient quality to serve as the basis for the Wulf band cross section assessment.

\section{Ozone cross section assessment}

Accurate knowledge of the magnitude and temperature dependence of the ozone absorption cross sections in the Wulf bands is critical to the success of the SAGE III retrievals of temperature/pressure, water vapor, and aerosol extinction. However, large discrepancies exist between different laboratory measurements of the Wulf band cross sections. Comparisons of candidate reference cross section databases reveal differences that are significantly larger than the reported uncertainties in the reference cross sections themselves. In addition, the ozone cross sections are highly temperature dependent in the Wulf bands, varying by $20 \%$ in the absorption peaks between $293 \mathrm{~K}$ and $203 \mathrm{~K}$. However, the temperature dependence of the SA cross section compilation, currently used in SAGE III processing, is only reported for a small portion of the Wulf bands (wavelengths up to $762 \mathrm{~nm}$ ). The SCIAMACHY reference cross section database includes the temperature dependence throughout the entire Wulf band region. In this section, we examine GAMS atmospheric measurements to provide a qualitative assessment of the accuracy of the reference absorption cross sections in the ozone Wulf bands. 


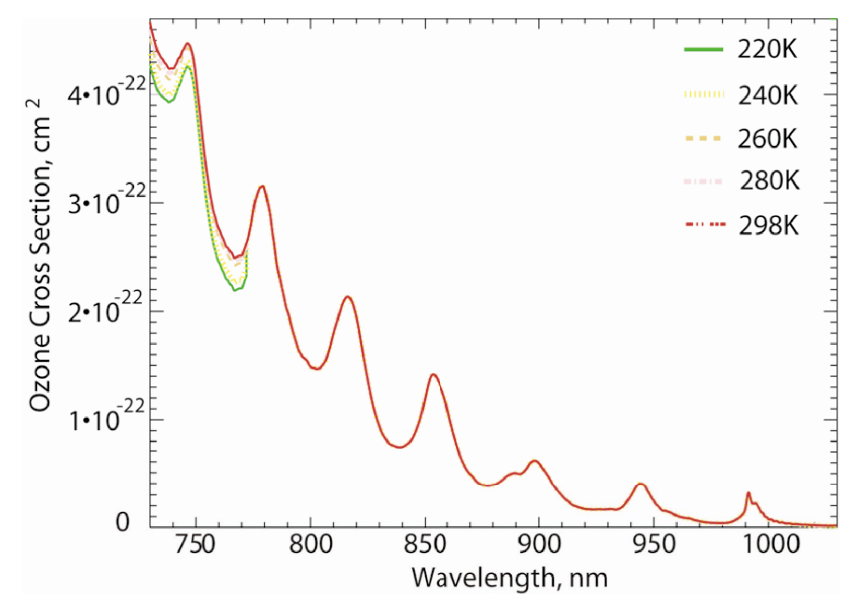

Fig. 11. Ozone Wulf band absorption cross sections from the compilation of Shettle and Anderson (1995).

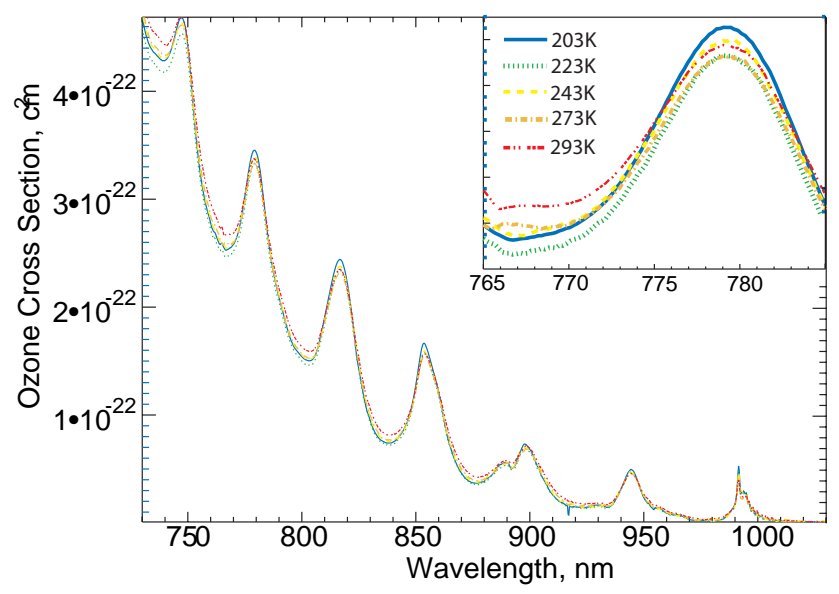

Fig. 12. Ozone Wulf band absorption cross sections from the SCIAMACHY reference data set.

\subsection{Reference cross-section databases}

Relative to the peak of the Chappuis band near $600 \mathrm{~nm}$, the ozone absorption spectrum in the Wulf bands is significantly weaker (factor of $\sim 50$ smaller at $850 \mathrm{~nm}$ ) and more structured. Accurate laboratory measurements of the weak absorptions in the Wulf bands are difficult to achieve due to the large ozone column densities required (e.g., Anderson et al., 1993) and, as a result, only a limited number of measurements are available. The reference ozone cross-section database currently used in the SAGE III operational data processing is based on the SA compilation that extends over a range of wavelengths from 407 to $1089 \mathrm{~nm}$. This compilation was developed by merging four different sets of laboratory measurements covering overlapping spectral regions (e.g., Anderson et al., 1990; 1991; 1993; Burkholder and Talukdar, 1994). The compilation is primarily based on room temperature measurements of the cross sections, with

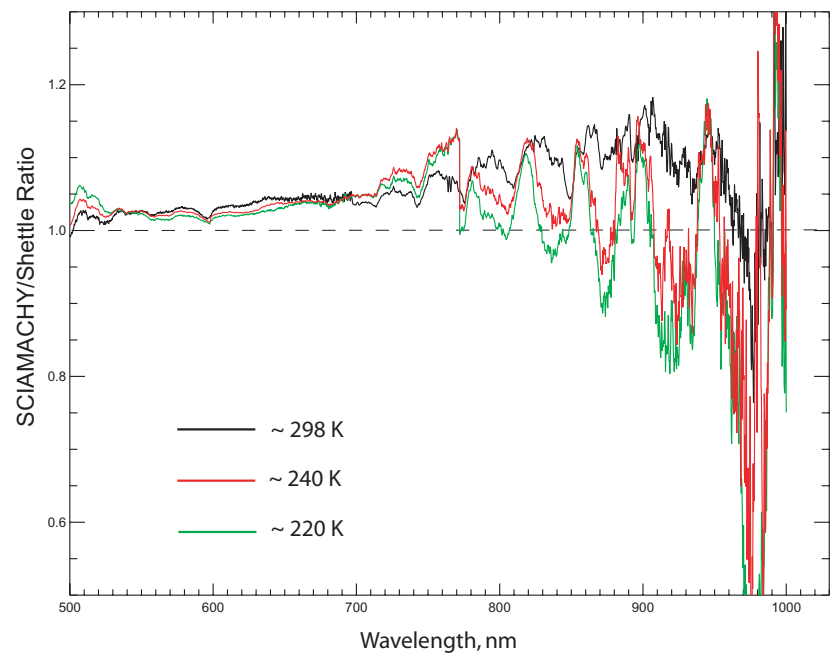

Fig. 13. Comparison of SCIAMACHY and Shettle and Anderson compilation ozone cross sections for three temperature regimes.

the notable exception of the Burkholder and Talukdar (1994) study that includes measurements at five temperatures ranging from $220 \mathrm{~K}$ to $298 \mathrm{~K}$, but only for wavelengths between 410 and $762 \mathrm{~nm}$. Note that recent measurements of the temperature dependence of the ozone cross sections near $760 \mathrm{~nm}$ by Enami et al. (2004) agree with the results from Burkholder and Talukdar (1994). The spectral resolution of the SA compilation varies between 1.6 to $4.0 \mathrm{~nm}$ and their reported uncertainty ranges from 1-2\% at wavelengths between 520 and $800 \mathrm{~nm}$, increasing to $2-5 \%$ between 800 and $850 \mathrm{~nm}$, with a further increase to about $10 \%$ near $950 \mathrm{~nm}$. The SA reference cross section compilation for the Wulf bands is shown in Fig. 11.

An alternative reference ozone spectroscopy data set produced for the SCIAMACHY satellite mission (Bogumil et al., 2003) is now available. Using the SCIAMACHY preflight model spectrometer, a self-consistent set of reference ozone cross sections were measured from 230 to $1075 \mathrm{~nm}$ at five different temperatures between $203 \mathrm{~K}$ and $293 \mathrm{~K}$. The SCIAMACHY ozone cross sections were measured with a spectral resolution that varies from approximately 0.21 to $0.5 \mathrm{~nm}$ and have a reported accuracy of better than $3.1 \%$ for cross sections larger than $10^{-23}$ (corresponding to wavelengths less than about $950 \mathrm{~nm}$ ). The SCIAMACHY reference cross sections in the Wulf bands are shown in Fig. 12.

Comparisons of the SA compilation with the SCIAMACHY cross-sections for three different temperature regimes are shown in Fig. 13. In the Chappuis band, the SCIAMACHY cross sections are a few percent larger than those reported in the SA compilation, but within the error bars of both sets of measurements. At the absorption peaks of the Wulf bands, however, the SCIAMACHY cross-sections are 10-15\% larger than those reported in the SA compilation. The $10 \%$ difference at $755 \mathrm{~nm}$ is consistent 
with the ozone cross section error inferred by Thomason and Taha (2003). The temperature dependence of the Wulf band absorption as reported in the SCIAMACY cross-section database is also evident in Fig. 13 and its omission is a serious deficiency of the SA compilation.

\subsection{Evaluation methodology}

The large discrepancy between the two laboratory measurements data sets and the lack of temperature dependence in the SA compilation is a significant issue for SAGE III data processing. Thomason and Taha (2003) already demonstrated that an anomaly in the SAGE III 755-nm aerosol extinction channel is likely the product of an incorrect ozone cross section in the SA compilation and it is likely that the T/p and water vapor retrievals have similar sensitivities. The atmospheric measurements from GAMS during SOLVE II offer a unique opportunity to evaluate these two reference cross section databases and make a recommendation for selecting the appropriate database to use in SAGE III data processing.

We can make this evaluation using data from three SOLVE II flights in which large DLOS ozone optical depths were observed by GAMS and the shape of the spectra was dominated by the Chappuis and Wulf band ozone absorption features (e.g., Fig. 5). In this case, we fit the GAMS optical depth spectra from these flights using the MLR approach described in Section 3 across the entire spectral range and use the fit residuals to assess the accuracy of the ozone reference cross sections. Assuming that the residuals in the Wulf band spectral region are produced solely by errors in the ozone cross sections used in the regression model, an estimate of that error in the ozone cross sections can be determined as

$\Delta \sigma_{O_{3}}(\lambda)=\frac{\Delta \tau(\lambda)}{n_{O_{3}}}$

where $\Delta \tau(\lambda)$ is the optical depth residual between the GAMS DLOS measurements and the MLR fitted values and $n_{O 3}$ is the retrieved ozone column density. This approach is at least approximately true since these residuals are obviously correlated with the Wulf band structure (e.g., Fig. 7). However, inaccurate water vapor and aerosol values can also create residuals in the fits. Water vapor is the dominant absorber at wavelengths beyond about $850 \mathrm{~nm}$ and when water vapor abundance is large, even small errors in fitting the water vapor features will produce large residuals. It should be noted, however, that any water vapor residual would be uncorrelated with the Wulf band structure. To minimize the effects of water vapor, we exclude measurement paths that may pass through the water-rich troposphere by limiting our analysis to GAMS data acquired at solar zenith angles less than $88^{\circ}$. Since DC-8 flight altitudes for solar acquisition legs were confined to the lower stratosphere, this will assure the measurement LOS is clearly above the troposphere. Deficiencies in the aerosol model can also impact the quality of the fits, but this will affect the overall baseline of the fit and

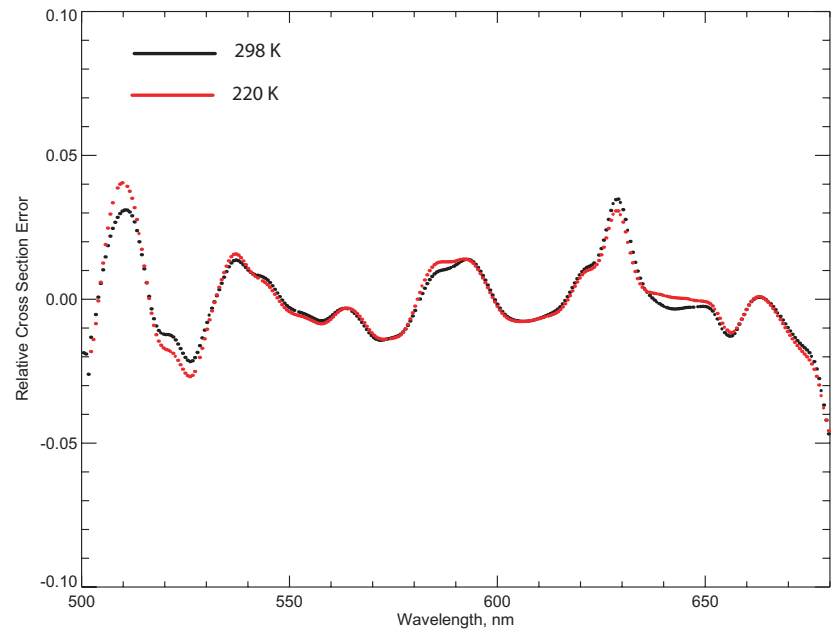

Fig. 14. Inferred errors in the Shettle and Anderson reference cross section compilation for the ozone Chappuis band.

not produce residuals with structure at the scale of the ozone cross sections. Since the shape of the aerosol component is severely constrained, any problem with fitting the aerosol component is likely to produce a DC or smoothly varying residual rather than exhibiting any significant spectral shape. Implicit in this approach is the assumption that the true errors in the reference cross sections are reasonably small. Feedback between large ozone cross section errors and the fit of the other parameters could significantly impact the quality of the fits and produce unpredictable results. Since the evaluation of the cross sections is made for a line-of-sight column and several geographically separated flight legs, there is no single 'temperature' for which these evaluations are representative, though all columns were clearly at "stratospheric" temperatures.

\subsection{Results}

To fulfill science priorities, the majority of the solar acquisition legs flown by the DC-8 during SOLVE II were executed at solar zenith angles near $90^{\circ}$ to facilitate data comparisons with SAGE III sunset occultation measurements and examine polar ozone chemistry. However, a few flights were designed to allow at least one set of measurements at relatively low air mass (small solar zenith angles) in addition to the nominal Sun runs near solar zenith angles of $90^{\circ}$ (e.g., flight of 19 January). These flights produced the largest differential ozone signals and, hence, offered the best opportunities to evaluate the quality of the ozone cross sections. The range of solar zenith angles encountered during each of the GAMS flights is included in Table 1. The flight of 19 January offered the ideal conditions for this study: a high sun elevation leg for normalization and the largest DLOS ozone optical depth observed during the entire SOLVE II mission. Solar acquisition legs 1, 2, 3, 4, and 7 were not included in our analysis 


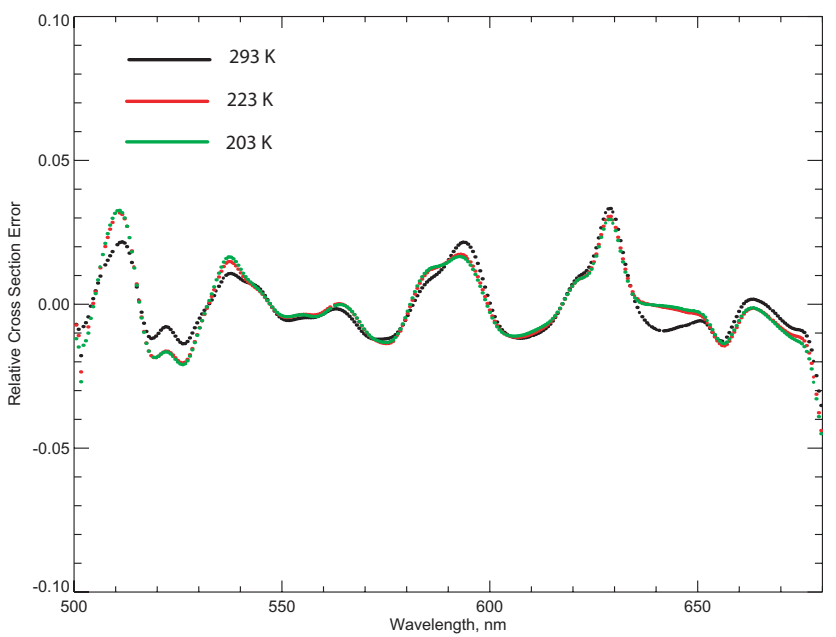

Fig. 15. Inferred errors in the SCIAMACHY reference cross sections for the ozone Chappuis band.

since the measurement solar zenith angles were greater than $88^{\circ}$. Still, over 80000 individual GAMS spectra are included in this sample.

Inferred cross section errors were initially derived from the spectral fits of the GAMS data using the SA compilation for $298 \mathrm{~K}$ and the SCIAMACHY cross sections for $293 \mathrm{~K}$. Meteorological data from the 19 January flight indicate that ambient temperatures along the GAMS LOS were as cold as 200-210 K, so cross section errors were also derived using the SA compilation for $220 \mathrm{~K}$ and the SCIAMACHY cross sections for both $223 \mathrm{~K}$ and $203 \mathrm{~K}$. For both the SA compilation (Fig. 14) and SCIAMACHY (Fig. 15) cases, the inferred cross section errors in the Chappuis region are generally less than a few percent, which is in agreement with the expected uncertainty in the reference cross sections. Although the SCIAMACHY ozone cross sections over the Chappuis are systematically larger than SA (see Fig. 13), their overall spectral shapes are similar with only small differences $(<1 \%)$. Therefore, it is expected that the residuals of the fits and, hence, the inferred errors shown in Figs. 14 and 15 have similar shape, although they are not identical. In the Wulf bands, the inferred cross section errors in the SA compilation (Fig. 16) are significantly larger than in the Chappuis and their shape is strongly correlated with the shape of the reference ozone cross sections. The large cross section errors inferred at wavelengths beyond $\sim 900 \mathrm{~nm}$ are due to the combination of the small magnitude of the ozone cross sections in that spectral region and limitations in fitting the residual water vapor absorption structure. These results imply that the SA compilation may be in error by as much as $10-20 \%$ in the Wulf bands, with the largest errors in the absorption peaks and valleys. The $10 \%$ cross section error near $755 \mathrm{~nm}$ for $220 \mathrm{~K}$ is in agreement with Thomason and Taha (2003). The inferred errors in the SCIAMACHY cross section database (Fig. 17) are significantly smaller than those for the SA com-

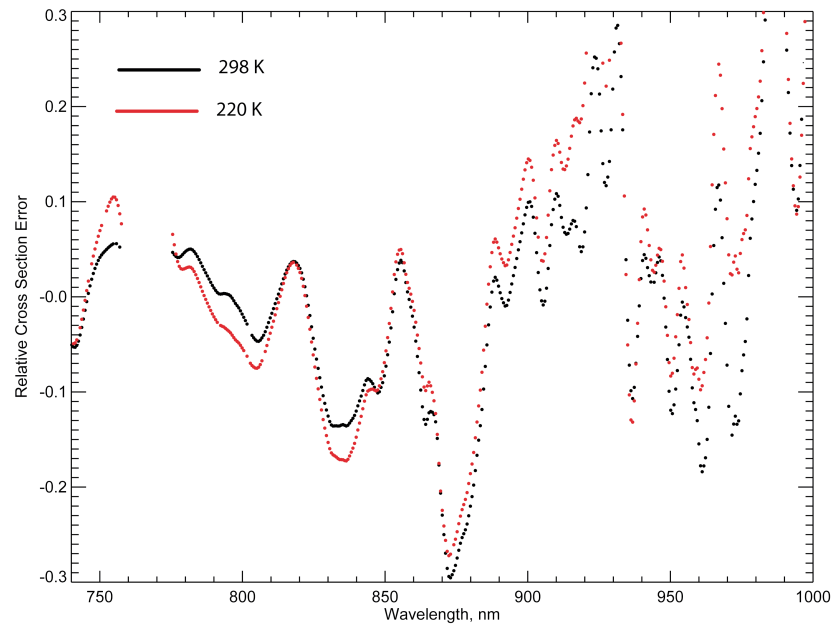

Fig. 16. Inferred errors in the Shettle and Anderson reference cross section compilation for the ozone Wulf bands.

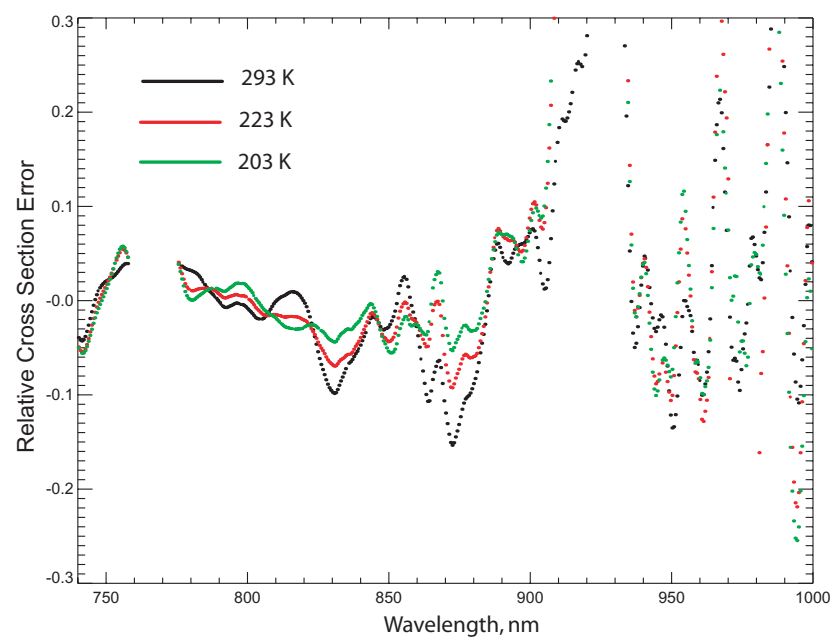

Fig. 17. Inferred errors in the SCIAMACHY reference cross sections for the ozone Wulf bands.

pilation, indicating that they fit the GAMS spectra better overall. The SCIAMACHY cross sections for stratospheric temperatures $(223 \mathrm{~K}$ and $203 \mathrm{~K})$ offer the best fits, but still produce relative errors of up to $5 \%$ with the largest errors also occurring near the peaks of the Wulf bands.

Empirical sets of cross sections were produced by adjusting the SA and SCIAMACHY cross sections by the relative errors derived from the GAMS analysis shown in the figures above. These "ideal" cross sections fit the GAMS optical depth spectra perfectly, producing essentially no residual. The adjusted SA compilation for $223 \mathrm{~K}$ and adjusted SCIAMACHY cross sections for $203 \mathrm{~K}$ are shown in Fig. 18. For comparison, the original reference cross sections are overplotted in the figure. In general, the SCIAMACHY cross sections match the "ideal" cross sections much better than 

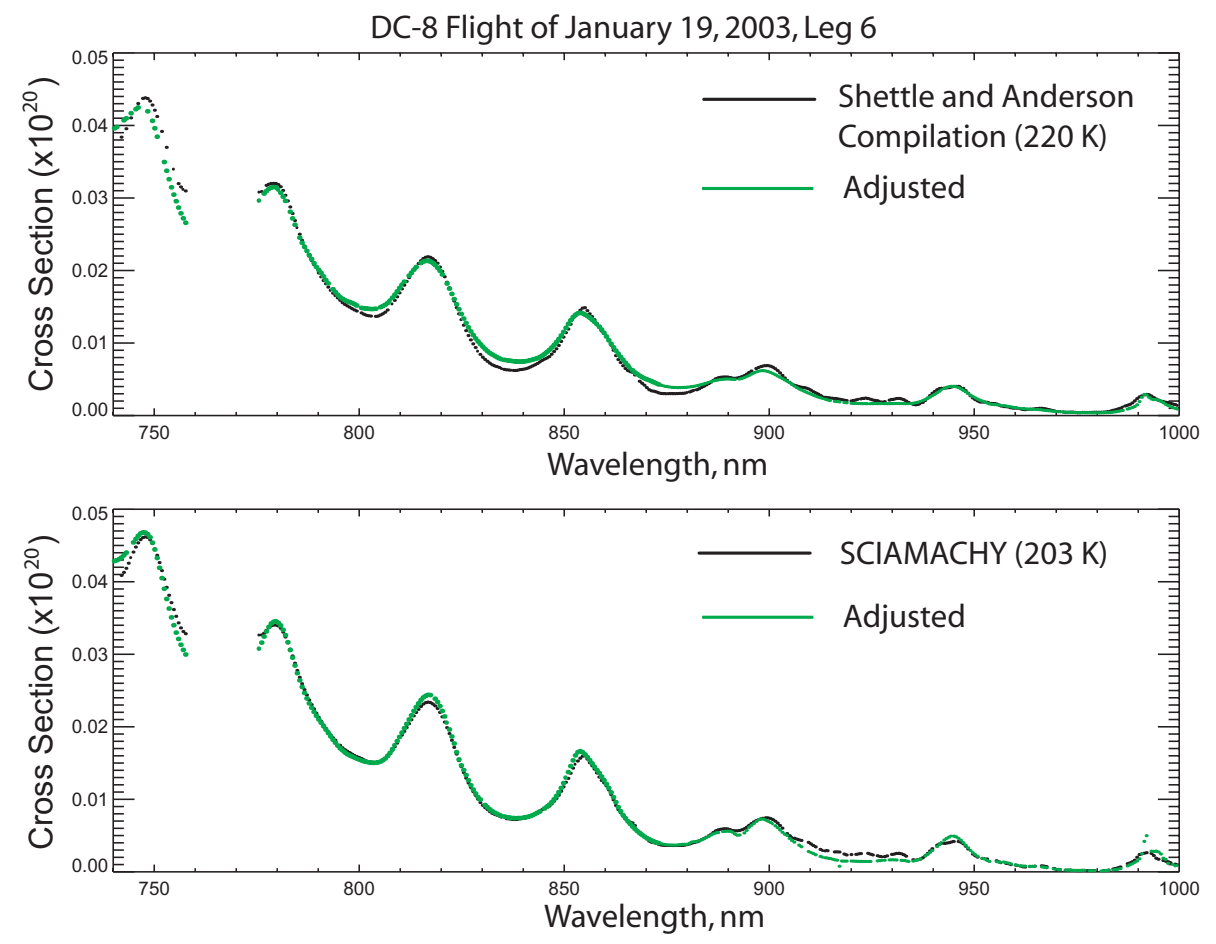

Fig. 18. Empirical cross sections (green lines) produced by adjusting Shettle and Anderson (top) and SCIAMACHY (bottom) reference cross sections. Reference cross sections are over-plotted for comparison (black lines).

the SA, which generally suggests that this data set is more robust that the older SA data set. The principal differences between the adjusted and original SCIAMACHY cross sections for $203 \mathrm{~K}$ are near the absorption peaks. The SA compilation for $223 \mathrm{~K}$ appears to underestimate the overall amplitude of the Wulf bands, being too small (large) near the absorption peaks (valleys), thus behaving as if it was effectively at coarser spectral resolution than reported. This behavior is consistent with the results of El Helou et al. (2005) who observed the line shape of the Wulf band absorption becoming narrower and more amplified at lower (stratospheric) temperatures resulting in an increase in the maximum cross section at the Wulf band peaks and a decrease in the minima between the peaks. El Helou et al. (2005) and Enami et al. (2004) hypothesize that this change in the shape of the ozone absorption profile is produced by changes in the molecular rotational distributions with temperature. The results for both the SA and SCIAMACHY data sets are less reliable beyond $900 \mathrm{~nm}$ due to the weaker ozone absorption and water vapor effects.

The ideal cross sections shown in Fig. 18 derived from the spectral fits of the GAMS data using SCIAMACHY and SA cross section data sets are not identical and, in fact, differ by as much as $5-10 \%$. This points to a limitation in the approach employed herein and supports the conclusion that the derived "ideal" cross sections are not sufficiently robust to use as a new cross section data base in and of themselves.
On the other hand, the measured spectral dependence observed by GAMS during SOLVE II is clearly more consistent with the SCIAMACHY set than the SA compilation. In fact, we believe that the relatively small but consistent differences produced by the SCIAMACHY comparison are sufficiently robust to conclude that the inferred cross section errors in the absorption peaks are likely to reflect reality.

\section{Summary and conclusion}

GAMS flew aboard the NASA DC-8 during the SOLVE II field campaign and collected over five million atmospheric spectra. Comparisons of GAMS DLOS optical depth and ozone column density products with coincident measurements from two independent instruments on board the DC-8 demonstrate the robustness and stability of the GAMS measurements. The GAMS atmospheric spectra were then utilized to assess the quality of reference ozone cross sections in the Wulf bands. Results from this assessment suggest that the ozone cross section compilation of Shettle and Anderson may be in error by as much as $10-20 \%$ in the Wulf bands and the lack of temperature dependence is a significant deficiency. On the other hand, the SCIAMACHY cross section database appears to be of better quality in the Wulf bands, but still may be underestimating the Wulf band absorption peaks by as much as $5 \%$, slightly larger than their stated uncertainty. Based on these result, we recommend 
that the SAGE III processing team implement the SCIAMACHY cross sections for routine data processing. We also recommend that additional laboratory measurements of these cross sections be pursued to further reduce their uncertainty and better quantify their temperature dependence. Our results also suggests that future measurements of ozone spectroscopy across the Chappuis and Wulf bands should be made with a single consistent experiment because such consistency is crucial for experiments like SAGE III where ozone measured in one spectral region is used to remove the effects of ozone absorption in another.

Acknowledgements. This research was supported by the National Aeronautics and Space Administration through the Upper Atmospheric Research Program. We thank L. Lait, M. Schoeberl, and P. Newman for providing the maps used in Fig. 3.

Edited by: K. Carslaw

\section{References}

Anderson, S. M., Morton, J., and Mauersberger, K.: Near-infrared absorption spectra of ${ }^{16} \mathrm{O}_{3}$ and ${ }^{18} \mathrm{O}_{3}$ : Adiabatic energy of the ${ }^{1} \mathrm{~A}_{2}$ state?, J. Chem. Phys., 93, 3826-3832, 1990.

Anderson, S. M., Maeder, J., and Mauersberger, K.: Effect of isotopic substitution on the visible absorption spectrum of ozone, J. Chem. Phys., 6351-6357, 1991.

Anderson, S. M., Hupalo, P., and Mauersberger, K.: Rotational structure in the near-infrared absorption spectrum of ozone, J. Chem. Phys., 737-739, 1993a.

Anderson, S. M., Hupalo, P., and Mauersberger, K.: Ozone absorption cross section measurements in the Wulf bands, Geophys. Res. Lett., 20, 1579-1582, 1993b.

Bevington, P.: Data Reduction and Error Analysis for the Physical Sciences, McGraw-Hill, New York, 164-186, 1969.

Bogumil, K., Orphal, J., Homann, T., Voigt, T. S., Spietz, P., Fleischmann, O., Vogel, A., Hartmann, M., Bovensmann, H., Frerik, J., and Burrows, J.: Measurements of molecular absorption spectra with the SCIAMACHY pre-flight model: Instrument characterization and reference data for atmospheric remote sensing in the 230-2380 nm region, J. Photochem. Photobiol. A.: Chem., 157, 167-184, 2003.

Bucholtz A.: Rayleigh-scattering calculations for the terrestrial atmosphere, Appl. Opt., 34, 2765-2773, 1995.

Burkholder, J. B. and Talukdar, R. K.: Temperature dependence of the ozone absorption spectrum over the wavelength range 410 to $760 \mathrm{~nm}$, Geophys. Res. Lett., 21, 581-584, 1994.

El Helou, Z., Churassy, S., Wannous, G., Bacis, R., and Boursey, E.: Absolute cross sections of ozone at atmospheric temperatures for the Wulf and the Chappuis bands, J. Chem. Phys., 122, $244311-$ 1-244311-9 2005.

Enami, S., Ueda, J., Nakano, Y., Hashimoto, S., and Kawasaki, M.: Temperature-dependent absorption cross sections of ozone in the Wulf-Chappuis band at 759-768 nm, J. Geophys. Res., 109, D05309, doi:10.1029/2003JD004097, 2004.

Livingston, J. M., Schmid, B., Russell, P. B., Eilers, J. A., Koyler, R. W., Redemann, J., Ramirez, S. A., Yee, J.-H., Swartz, W. H., Trepte, C. R., Thomason, L. W., Pitts, M. C., Avery, M. A., Ran- dall, C. E., Lumpe, J. D., Bevilacqua, R. M., Bittner, M., Erbertseder, T., McPeters, R. D., Shetter, R. E., Browell, E. V., Kerr, J. B., and Lamb, K.: Retrieval of ozone column content from airborne Sun photometer measurements during SOLVE II: Comparison with coincident satellite and aircraft measurements, Atmos. Chem. Phys., Vol. 5, 243-286, 2005.

Orphal, J.: A critical review of the absorption cross sections of $\mathrm{O}_{3}$ and $\mathrm{NO}_{2}$ in the ultraviolet and visible, J. Photochem. Photobiol. A: Chemistry 157, 185-209, 2003.

NASA Langley Research Center: SAGE III algorithm theoretical basis document: Solar and lunar algorithm, Rep. LaRC 475-00108, Vers. 2.1, Hampton, Virginia, 2002.

Pitts, M. C.: Retrieval of temperature and pressure profiles for the Stratospheric Aerosol and Gas Experiment III, Ph.D. thesis, The College of William and Mary, 162, 1999.

Pitts, M. C., Hansen, G. M., and Lucker, P. L.: An airborne A-band spectrometer for remote sensing of aerosol and cloud properties, in: Remote Sensing of Clouds and the Atmosphere VII, edited by: Schaefer, K. P., Lado-Bordowsky, O., Comeron, A., Picard, R. H., SPIE, Vol. 4882, 353-362, 2003.

Refaat, T. F., Abedin, M. N., Farnsworth, G. R., Garcia, C. S., Zawodny, J. M.: Characterization of custom-designed chargecoupled devices for applications to Gas and Aerosol Monitoring Sensorcraft instrument, in Spaceborne Sensors II, Peter Tchoryk, Brian Holz, Editors, Proc. of SPIE, Vol. 5798, 226-233, 2005.

Russell, P. B., Livingston, J. M., Dutton, E. G., Pueschel, R. F., Reagan, J. A., DeFoor, T. E., Box, M. A., Allen, D., Pilewskie, P., Herman, B. M., Kinne, S. A., and Hofmann, D. J.: Pinatubo and pre-Pinatubo optical-depth spectra: Mauna Loa measurements, comparisons, inferred particle size distributions, radiative effects, and relationship to lidar data, J. Geophys. Res., 98, 22, 969-22,985, 1993a.

Russell, P. B., Livingston, J. M., Pueschel, R. F., Reagan, J. A., Browell, E. V., Toon, G. C., Newman, P. A., Schoeberl, M. R., Lait, L. R., Pfister, L., Gao, Q., and Herman, B. M.: PostPinatubo optical depth spectra vs. latitude and vortex structure: Airborne tracking sunphotometer measurements in AASE II, Geophys. Res. Lett., 20, 2571-2574, 1993b.

Russell, P. B., Livingston, J. M., Schmid, Eilers, B. J., Kolyer, R., Redemann, J., Ramirez, S., Yee, J.-H., Swartz, W., Shetter, R., Trepte, C., Thomason, L., Risley, A., Wenny, B., Zawodny, J., Chu, W., Pitts, M., Lumpe, J., Randall, C., and Bevilacqua, R.: Aerosol optical depth measurements by airborne Sun photometer in SOLVE II: Comparison to SAGE III, POAM III and airborne spectrometer measurements, Atmos. Chem. Phys., 4, 7291-7353 , 2005.

Schmid, B., Redemann, J., Russell, P. B., Hobbs, P. V., Hlavka, D. L., McGill, M. J., Holben, B. N., Welton, E. J., Campbell, J. R., Torres, O., Kahn, R. A., Diner, D. J., Helmlinger, M. C., Chu, D. A., Robles-Gonzalez, C., and De Leeuw, G.: Coordinated airborne, spaceborne, and ground-based measurements of massive, thick aerosol layers during the dry season in Southern Africa, J. Geophys. Res., 108 (D13), 8496, doi:10.1029/2002JD002297, 2003.

Shetter, R. E. and Muller, M.: Photolysis frequency measurements using actinic flux spectroradiometry during PEM-Tropics mission: Instrumentation description and some results, J. Geophys. Res., 104, 5647-5661, 1999.

Shettle, E. P. and Anderson, S. M.: New visible and near IR ozone 
absorption cross-sections for MODTRAN, Proceedings of the 17th Annual Conference of Atm. Transmission Models, 8-9 June 1994, PL-TR-95-2060, edited by: Anderson, G. P., Picard, R. H., and Chetwynd, J. H., 335-345,1995.

Swartz, W. H., Yee, J.-H., Shetter, R. E., Hall, S. R., Lefer, B. L., Livingston, J. M., Russell, P. B., Browell, E. V., Avery, M. A.: Column ozone and aerosol optical properties retrieved from direct solar irradiance measurements during SOLVE II, Atmos. Chem. Phys., 5, 611-622, 2005.
Thomason, L. W., Chu, W. P., and Pitts, M. C.: The stratospheric aerosol and gas experiment III, paper presented at the 22nd General Assembly, Intl. Union of Geod. and Geophys., Birmingham, UK, 1999.

Thomason, L. W. and Taha, G.: SAGE III aerosol extinction measurements: Initial results, Geophys. Res. Lett., 30, 33-35, 2003. 